\title{
An Uncertainty Theory-based Model for Stability Assessment of Rocks Surrounding Hydraulic Tunnels
}

\author{
Xiao Sun ${ }^{1,2}$ \\ ${ }^{1}$ School of Hydraulic and Ecology Engineering, Nanchang Institute of Technology, Nanchang, Jiangxi,330099, China \\ ${ }^{2}$ Jiangxi Engineering Research Center of Water Engineering Safety and Resources Efficient Utilization, Nanchang, \\ Jiangxi,330099, China
}

Received 8 May 2016; Accepted 3 November 2016

\begin{abstract}
Traditional certainty approaches for assessing the stability of the surrounding rocks of hydraulic tunnels fail to consider the stochasticity and fuzziness of parameters. The uncertainty theory-based model was adopted in the present study to resolve the defects arising from high-impact parameter selection and parameter values of rock masses on surrounding rock stability. First, a qualitative analysis on surrounding rock stability of hydraulic tunnels was performed using mathematical techniques. The results were used to propose an unascertained measure evaluation model to assess the surrounding rock stability of hydraulic tunnels. A comprehensive evaluation indicator system for surrounding rock stability was established. Next, the classification criteria matrix for the evaluation indicators and the unascertained measure recognition matrix under a single indicator were built. The above tools were used to assess the surrounding rock stability grade. The comprehensive evaluation model for surrounding rock stability was obtained. This model was then applied to an engineering case involving the diversion tunnel of Changdian Hydropower Station in Liaoning Province. The assessment result was compared with the actual of the project. The comprehensive evaluation model enabled the full consideration of uncertain and concealed parameters of the rock masses. The comprehensive measure vector calculated for the rock mass showed that the stability grade is $C_{3}$, that is, the surrounding rock stability is poor. Field investigation indicated small cracks in the surrounding rocks with local plastic deformation. Several unsupported rocks had collapsed or undergone deformation damage. The appraisal showed that the surrounding rocks had poor stability; this result was consistent with the model calculation. The proposed model provides reference for further studies on surrounding rock stability assessment of hydraulic tunnels. Such studies can be used to improve designs and project construction.
\end{abstract}

Keywords: Hydraulic Tunnel, Surrounding Rock, Uncertainty Theory, Stability

\section{Introduction}

China has recently witnessed a rise of hydraulic construction projects, where new hydraulic techniques are applied and tested. Hydraulic tunnels are important structures for water conveyance, drainage, flood control, and power generation in hydro-junction projects. The surrounding rock stability of hydraulic tunnels strongly influences the construction and operation safety of the entire hydraulic project. Numerical simulation as a type of deterministic analysis is widely used in surrounding rock stability assessment. A few mechanical parameters of the rock masses are first determined by indoor experiments. Then the excavation process is simulated, and the surrounding rock stability is assessed based on whether the plastic region has been penetrated. However, the real situation is that the presence of joints and cracks in the rock masses as well as the effects of water and crustal stress lead to high uncertainty in the mechanical parameters of the rock masses. If rock mass parameters determined in indoor experiments are directly used for numerical simulation, then the estimated result usually differs greatly from the findings of field investigations. Parameter selection and value determination of the rock masses is a major challenge in

*E-mail address: lanchong1024@126.com

ISSN: 1791-2377 @ 2016 Eastern Macedonia and Thrace Institute of Technology. All rights reserved. surrounding the rock stability assessment of hydraulic tunnels. Therefore, building a model to evaluate the surrounding rock stability of hydraulic tunnels that fully considers the uncertainty and hidden nature of rock mass parameters is of high importance.

We used uncertainty theory and engineering practice to assess surrounding rock stability for hydraulic tunnels. The comprehensive evaluation indicator system was proposed by using fuzzy mathematics and statistical theories. After that, we established an unascertained measure evaluation model for surrounding rock stability in hydraulic tunnels.

\section{State of the art}

Traditional surrounding rock stability analysis for hydraulic tunnels is generally based on the certainty method, which involves a quantitative calculation and comparison of a safety factor with the allowable safety factor. Whether supports or tunnel lining is needed is then determined based on the safety factor. A qualitative evaluation of the surrounding rock safety of the hydraulic tunnels is followed. The certainty method is divided into three categories: the engineering-geology analog method, the analytical method, and the numerical method. Pinto et al. [1],[2] conducted indoor tests on parameter anisotropy for different types of 
rock masses and summarized the variation pattern of the tested parameters. Jeage and Rarnamutrh [3],[4] observed the variations of mechanical performance of the rock masses and obtained the influence of mechanical parameters of the rock masses on overall strength by changing one parameter of the rock mass. Amadei [5] summarized the variations of rock mass mechanical parameters based on numerous indoor and outdoor tests. Singh [6] applied the equivalent medium theory to study rock mass mechanical parameters. Jose [7] thoroughly investigated the parameters of the structural plane and fracture surface in the layered rock mass, proposing that rock mass parameters strongly influenced on rock mass strength. Lashkaripou and Passaris [8] used numerous indoor and outdoor tests to construct a prediction model for rock mass mechanical parameters. Trollope, L Jing, and Googman et al. [9],[10],[11] successfully applied block theory to the study of mechanical behaviors of discontinuous rock masses, and the theory was proved to be applicable to engineering. Chen et al. [12] performed parameter retrieval to study the surrounding rock strength parameters. They proposed the inverse method for strength parameters. Wang et al. [13] applied back analysis of the measured displacement to the sensitivity analysis of surrounding rock mechanical parameters. Qu et al. [14] used FINAL Analysis Software to study the effect of different surrounding rock mechanical parameters on the operation of hydraulic tunnels. They also assessed the sensitivity of each parameter. Liu et al. [15] applied liquid-solid coupling theory and Fast Lagrangian Analysis of Continua to assess the stability of surrounding rocks in tunnels. They discussed the effect of excavation disturbance and internal water pressure on surrounding rock stability. Fan, $\mathrm{Xu}$, and Peng [16] used ANSYS software to conduct a numerical simulation on surrounding rock stability in hydraulic tunnels. Their study shed new light on relevant engineering projects and academic research. Li, Zheng, and Kang [17] used the strength reduction finite element method to calculate the safety factor as a measure of surrounding rock stability in tunnels. They used gray relational analysis to analyze the sensitivity of the influencing factors of surrounding rock stability. The research findings can inform the grading of surrounding rock stability and tunnel optimization design. Zheng and Wang used a model experiment and elasto-plastic finite element method was used to discuss the surrounding rock stability and failure mechanism of tunnels. Their study provided position and morphology of the fracture surface of surrounding rocks. Jian Deng [19] and Hao used the block theory and programming technique for special geological conditions where the rock mass mechanical parameters are difficult to obtain to qualitatively analyze surrounding rock stability. Their research findings can guide the supporting of unstable surrounding rocks. Most of the studies cited above use deterministic analysis to obtain rock mass mechanical parameters, based on which surrounding rock stability is assessed for hydraulic tunnels. To do this, the concrete values of rock mass parameters are first determined by indoor tests, parameter retrieval, and the back analysis of measured displacement. Then these values are introduced into numerical simulation aided by software. However, the major shortcoming of this approach is that ideal parameter values are used instead of the actual values. The uncertainty and fuzziness of rock mass mechanical parameters arising from discontinuity of the rock masses are dismissed.
Addressing this defect, we use the uncertainty theory-based approach is combined with mathematical techniques to assess stability. An unascertained measure evaluation model is proposed in our study.

The remaining contents of the article are organized as follows: Section 3 describes the evaluation indicator system for surrounding rock stability as well as the establishment of the unascertained measure function and unascertained measure evaluation model. Section 4 demonstrates the reliability of the proposed model through an engineering case. The last section provides a summary and conclusions.

\section{Methodology}

\subsection{Comprehensive Assessment Index System for Surrounding Rock \\ 3.1.1 Selection of Indexes}

A total of 12 indexes were selected based on relevant standards and existing research findings as assessment indexes in the assessment model. These indexes consider the influences of various factors, such as rock strength, rock mass integrity, state, and the orientation of structural plane, groundwater, and in-situ rock stress, on surrounding rock. They include the uniaxial compressive strength and rebound value of rock, the P-wave velocity in rock, the integrity index of rock mass, the volumetric joint count, rock-quality designation $(R Q D)$, the strength of the structural plane, the friction coefficient between structural planes, the groundwater seepage velocity, the angle between main structural plane and tunnel axis, the dip angle of main structural plane, and the angle between maximum principal stress and tunnel axis.

\subsubsection{Assessment Index Scales}

The stability of the rock surrounding hydraulic tunnels was classified into four classes according to the classification criteria listed in Appendix 2 (hydraulic tunnel surrounding rock classification based on engineering geology) of the Construction Specifications on Underground Excavating Engineering of Hydraulic Structures. The judgement set is $\left(C_{1}, C_{2}, C_{3}, C_{4}\right)$, with $C_{1}, C_{2}, C_{3}$ and $C_{4}$ representing stable, basically stable, less stable, and unstable, respectively. Table 1 shows the surrounding rock stability classification for hydraulic tunnels. Table 2 presents the scales of the indexes.

Table 1. Surrounding rock stability classification for hydraulic tunnels

\begin{tabular}{|c|c|c|}
\hline No. & Surrounding rock characteristics & $\begin{array}{c}\text { Stability } \\
\text { class }\end{array}$ \\
\hline 1 & $\begin{array}{l}\text { The surrounding rock will maintain stability for a } \\
\text { long time period and usually contains no unstable } \\
\text { block. }\end{array}$ & Stable \\
\hline 2 & $\begin{array}{c}\text { The surrounding rock is stable overall and does } \\
\text { not deform plastically; spalling may occur } \\
\text { locally. }\end{array}$ & $\begin{array}{c}\text { Basically } \\
\text { stable }\end{array}$ \\
\hline 3 & $\begin{array}{c}\text { The surrounding rock, typically intact soft rock, } \\
\text { undergoes localized plastic deformation and may } \\
\text { collapse or fail without support and may be } \\
\text { temporarily stable. }\end{array}$ & Less stable \\
\hline 4 & $\begin{array}{l}\text { The surrounding rock will maintain stability for a } \\
\text { short time period and is prone to large-scale } \\
\text { deformation of various types and even failure. }\end{array}$ & Unstable \\
\hline
\end{tabular}


Table 2. Scales of assessment indexes

\begin{tabular}{|c|c|c|c|c|c|c|c|}
\hline \multirow{2}{*}{ No. } & \multirow{2}{*}{ Assessment index $x_{i}$} & \multirow{2}{*}{ Symbols } & \multirow{2}{*}{ Units } & \multicolumn{4}{|c|}{ Surrounding rock stability class } \\
\hline & & & & $C_{1}$ & $C_{2}$ & $C_{3}$ & $C_{4}$ \\
\hline 1 & Uniaxial compressive strength & - & $M P a$ & 100 & 60 & 30 & 15 \\
\hline 2 & Rebound value & $r$ & - & 45 & 35 & 25 & 15 \\
\hline 3 & P-wave velocity & $V$ & $m / s$ & 5500 & 4500 & 3500 & 2500 \\
\hline 4 & Integrity index of rock mass & $K_{V}$ & - & 0.75 & 0.55 & 0.4 & 0.2 \\
\hline 5 & Volumetric joint count & $J_{V}$ & $m^{3}$ & 3 & 10 & 20 & 30 \\
\hline 6 & $R Q D$ & - & - & 90 & 70 & 50 & 30 \\
\hline 7 & $\begin{array}{l}\text { Strength coefficient of structural } \\
\text { plane }\end{array}$ & $K_{f}$ & - & 0.8 & 0.6 & 0.4 & 0.2 \\
\hline 8 & Friction coefficient & - & - & 0.6 & 0.4 & 0.3 & 0.15 \\
\hline 9 & Groundwater seepage velocity & - & $m^{3} / s$ & 1 & 10 & 25 & 125 \\
\hline 10 & $\begin{array}{l}\text { Angle between main structural plane } \\
\text { and tunnel axis }\end{array}$ & - & rad & 60 & 50 & 40 & 30 \\
\hline 11 & Dip angle of main structural plane & - & rad & 70 & 50 & 35 & 20 \\
\hline 12 & $\begin{array}{l}\text { Angle between maximum principal } \\
\text { stress structural plane and tunnel axis }\end{array}$ & - & rad & 30 & 40 & 50 & 60 \\
\hline
\end{tabular}

\subsection{Comprehessive Assessment Model for Sourrounding} Rock Stability Analysis

\subsubsection{Construction of a classification standard matrix and} single-index identification subsystems

The stability of the rock surrounding hydraulic tunnels was classified Relevant mathematical theory was used to create a classification standard matrix of $x_{i j}$, the observed value of $I_{j}(j=1,2 \mathrm{~L} m)$ of surrounding rock $x_{i}(i=1,2 \mathrm{~L} n)$ :

$$
A=\left[\begin{array}{c}
I_{1} \\
I_{2} \\
\vdots \\
I_{n}
\end{array}\right] \cdot\left[\begin{array}{ccccc}
a_{11} & a_{22} & \cdots & a_{k} & a_{1 k} \\
a_{21} & a_{21} & \cdots & a_{2 k} \\
\vdots & \vdots & \ddots & \vdots \\
a_{m 1} & a_{m 2} & \cdots & a_{m k}
\end{array}\right]=\left(a_{i j}\right)_{m \times k}
$$

where where $a_{i j}$ is the standard value of index $I_{j}$ of surrounding rock $x_{i}$ at scale $\mathrm{j}$. In the assessment model presented in this section, $\left\{F_{1}, F_{2}, F_{3}, F_{4}\right\}$ represents the judgement set $\left(C_{1}, C_{2}, C_{3}, C_{4}\right)$, with $F_{1}, F_{2}, F_{3}$ and $F_{4}$ denoting stable, basically stable, less stable, and unstable, respectively; and $I_{1}, I_{2}, \mathrm{~L}, I_{12}$ are the 12 indexes that affect the stability of surrounding rock.

Each a measure function $u_{i j}(x)$ was constructed. Then the function value at each quality class $k(k=1,2, \mathrm{~L} K)$, denoted as $u_{i j k}$, was obtained. The uncertainty measure matrices for single-index identification were constructed as follows:

$u_{i}=\left(\begin{array}{cccc}u_{i 11} & u_{i 12} & \cdots & u_{i 1 k} \\ u_{i 21} & u_{i 22} & \cdots & u_{i 2 k} \\ \vdots & \vdots & \ddots & \vdots \\ u_{i m 1} & u_{i m 2} & \cdots & u_{i m k}\end{array}\right)=\left(u_{i j k}\right)_{m \times n}$

where the t-th row consists of observed values of $\mathrm{t}$-th measure of $x_{i}$ for various quality classes and the s-th column consists of observed values of different indexes of $x_{i}$ for the s-th quality class.

The weight vector of each index, denoted $w^{(i)}$, can be expressed as: $w^{(i)}=\left(w_{1}{ }^{(i)}, w_{2}{ }^{(i)}, \cdots, w_{m}{ }^{(i)},\right)^{T} \quad 0 \leq w_{j}^{(i)} \leq 1, \sum_{k=1}^{m} w_{k}^{(i)}$

where where $w_{j}^{(i)}$ is the weight, or relative importance, of $I_{j}$ for sample $x_{i}$. Normally, its value varies between different samples.

\subsubsection{Construction of uncertainty measure functions}

Linear uncertainty measure functions are the most widely used and simplest measure functions and are widely applied in natural science. Therefore, this study adopts linear uncertainty measure functions. Uncertainty measure functions for the 12 assessment indexes were constructed using the aforementioned index scales. Fig.1 to Fig.12 depicts these functions.

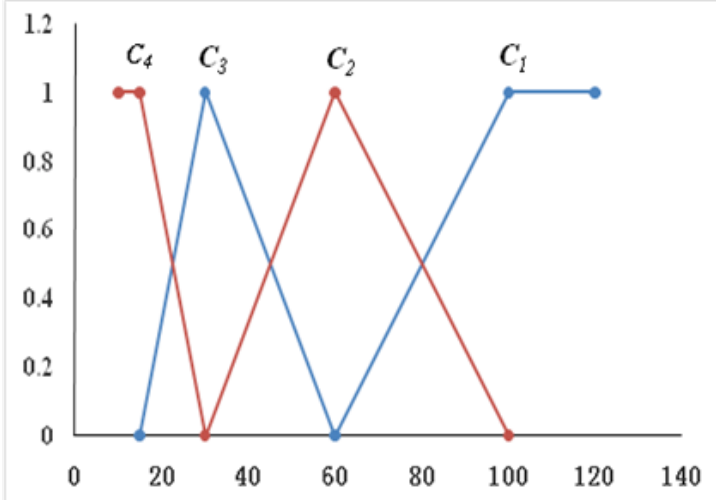

Fig. 1. Uniaxial compressive strength

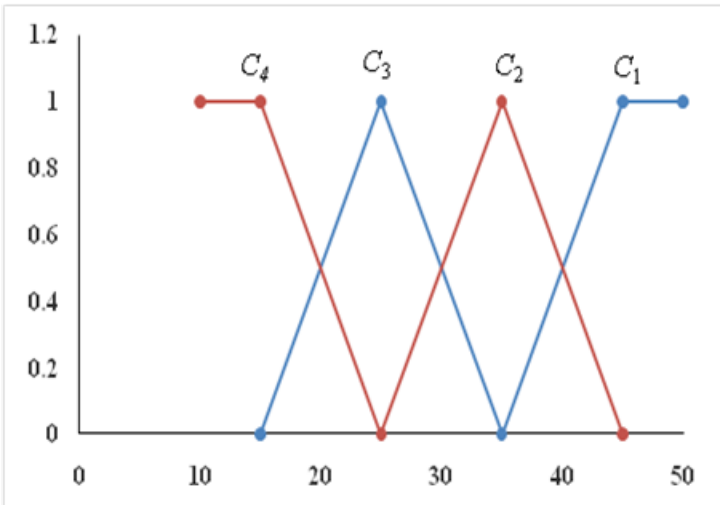

Fig. 2. Rebound Value 


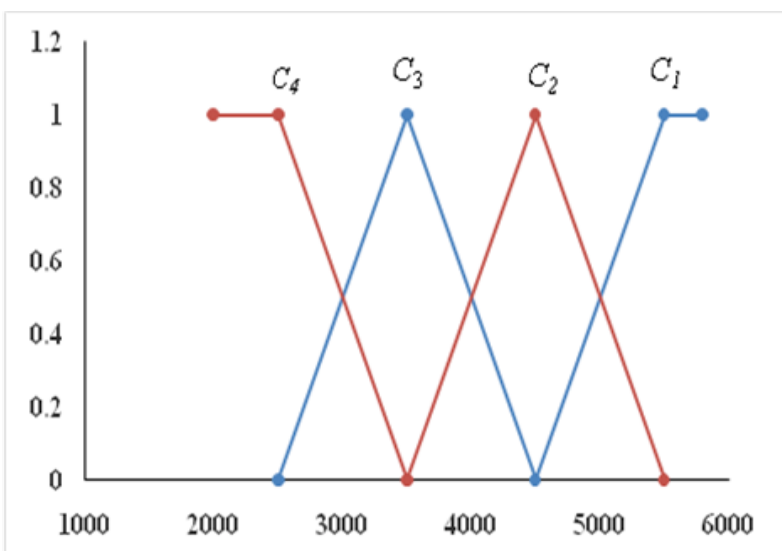

Fig. 3. P-wave velocity

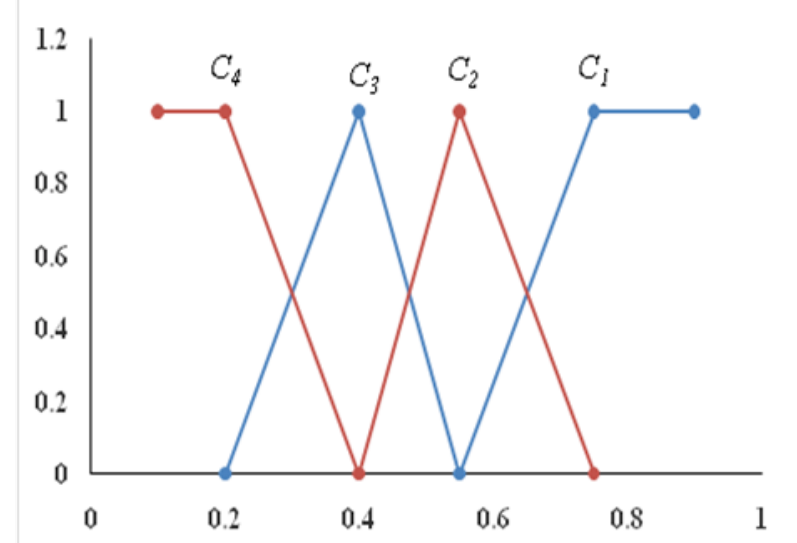

Fig. 4. Intergrity index of rock mass

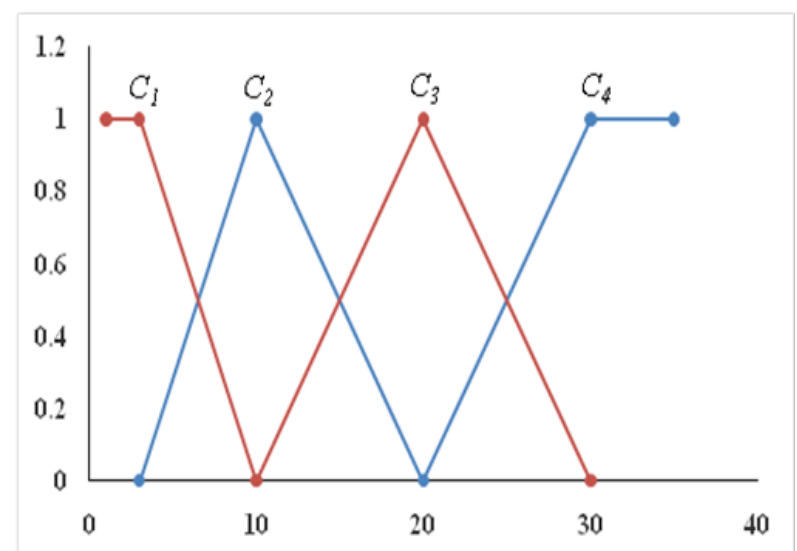

Fig. 5. Volumetric joint count

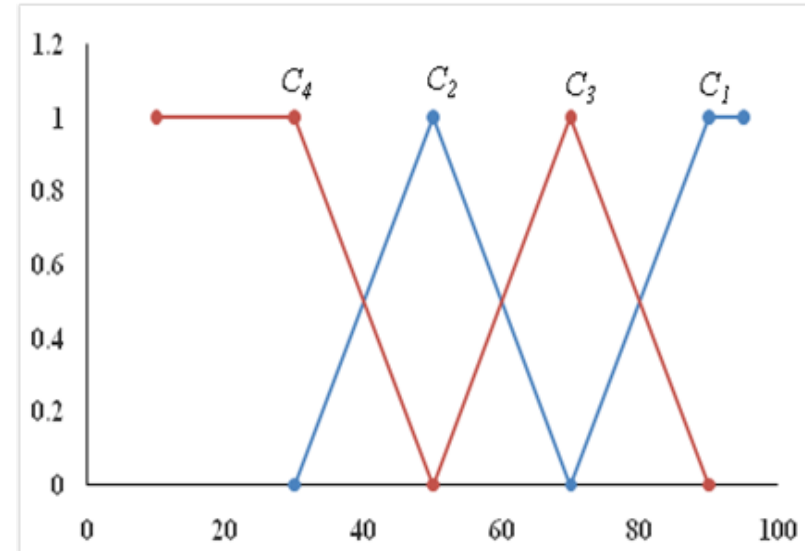

Fig. 6. $R Q D$

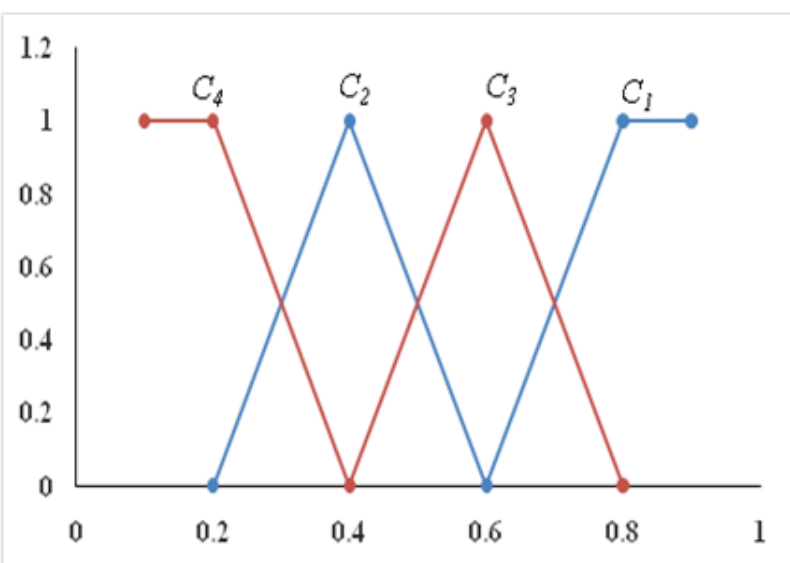

Fig. 7. Strength coefficient of structural plane

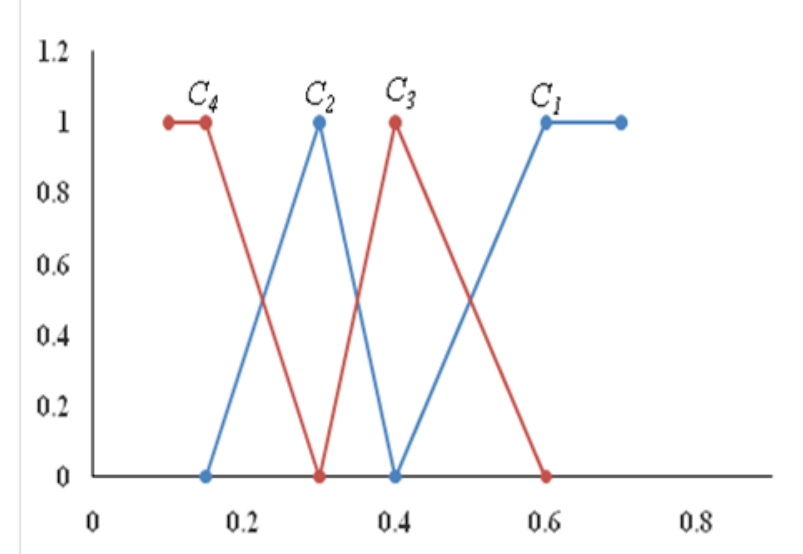

Fig. 8. Friction coefficient

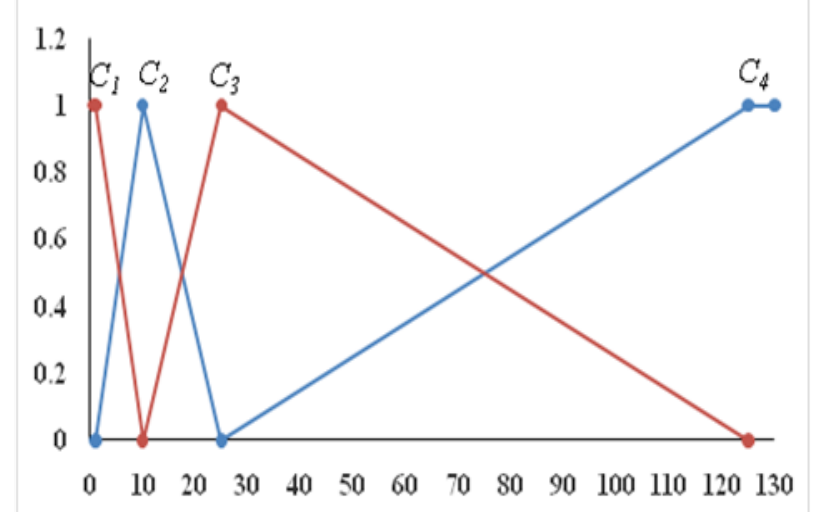

Fig. 9. Groundwater seepage velocity

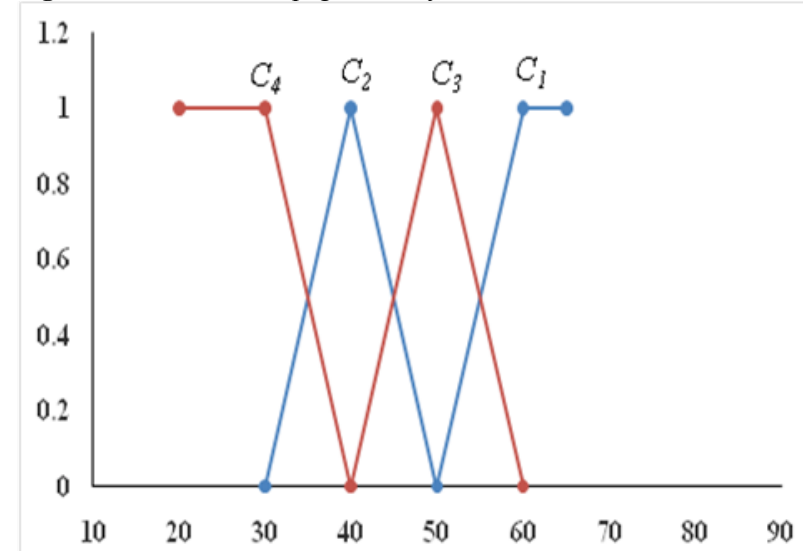

Fig. 10. Angle between main structural plane and tunnel axis 


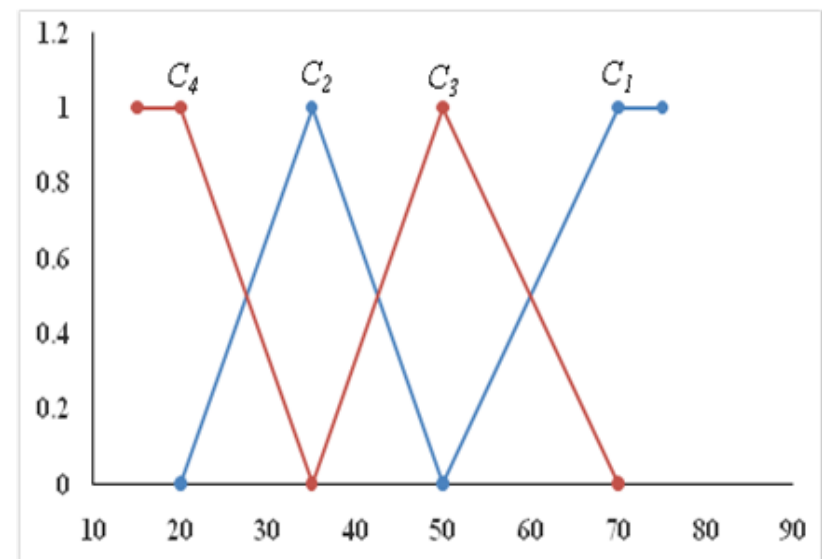

Fig. 11. Dip angle of main structural plane

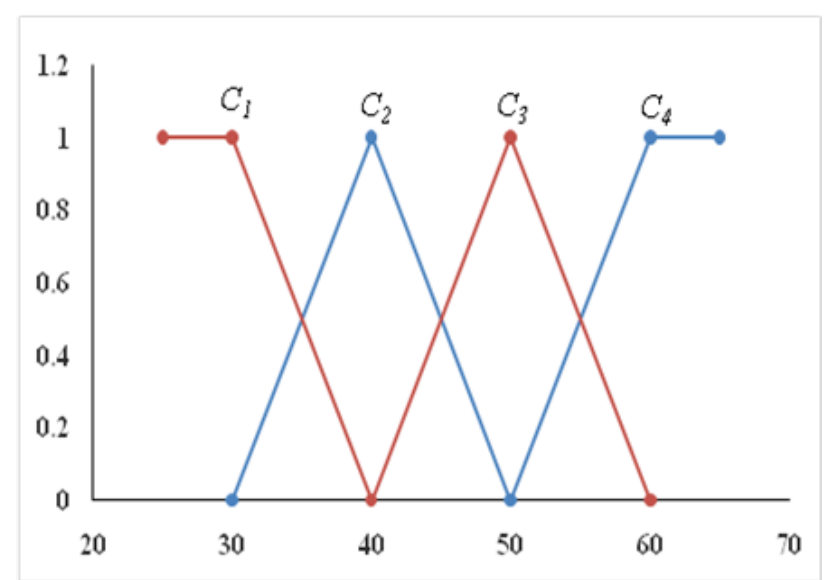

Fig. 12. Angle between maximum principal tress structural plane and tunnel axis

\subsubsection{Assessment Criteria}

This study used confidence levels as the assessment criteria. A threshold confidence level, denoted as $\lambda(\lambda>0.5)$ was preset. In this study, the threshold was set at 0.6. If $F_{i}>F_{i+1}$, then $\left\{F_{1}, F_{2}, \mathrm{~L} F_{k}\right\}$ is a normal sequence. Let:

$k_{0}=\min _{k}\left(k: \sum_{i=1}^{k} u_{i j} \geq \lambda, 1 \leq k \leq K\right)$

then $x_{i}$ falls under class $k_{0}$, i.e. $F_{k_{0}}$.

\section{Result analysis and discussion}

\subsection{A Case Study of a Project} 4.1.1 Project Overview

The unascertained information-based comprehensive assessment model was applied to stability analysis of the rock surrounding the power diversion tunnel at the Changdian Hydropower Station in Liaoning Province. Geological data of the surrounding rock along a certain section of the tunnel were acquired through a geological survey. Table 3 lists several data used in this study.

Table 3. Parameters of the rock surrounding the power diversion tunnel at the Changdian Hydropower Station

\begin{tabular}{|c|c|c|c|c|c|}
\hline No. & & Parameters & Symbols & Value & Units \\
\hline 1 & \multirow{3}{*}{ Rock strength } & Uniaxial compressive strength & - & 86 & $M P a$ \\
\hline 2 & & Rebound value & $r$ & 35.7 & - \\
\hline 3 & & P-wave velocity & $V$ & 2900 & $m / s$ \\
\hline 4 & \multirow{3}{*}{$\begin{array}{l}\text { Rock mass } \\
\text { integrity }\end{array}$} & Integrity index of rock mass & $K_{V}$ & 0.58 & - \\
\hline 5 & & Volumetric joint count & $J_{V}$ & 12 & $m^{3}$ \\
\hline 6 & & $R Q D$ & - & 60 & - \\
\hline 7 & \multirow{2}{*}{$\begin{array}{c}\text { State of } \\
\text { structural plane }\end{array}$} & Strength coefficient of structural plane & $K_{f}$ & 0.37 & - \\
\hline 8 & & Friction coefficient & - & 0.24 & - \\
\hline 9 & & Groundwater seepage velocity & - & 40 & $m^{3} / s$ \\
\hline 10 & \multirow{2}{*}{$\begin{array}{l}\text { Orientation of } \\
\text { structural plane }\end{array}$} & $\begin{array}{l}\text { Angle between main structural plane } \\
\text { and tunnel axis }\end{array}$ & - & 30 & rad \\
\hline 11 & & Dip angle of main structural plane & - & 70 & rad \\
\hline 12 & & $\begin{array}{l}\text { Angle between maximum principal } \\
\text { stress structural plane and tunnel axis }\end{array}$ & - & 55 & rad \\
\hline
\end{tabular}

\subsubsection{Single-index Measure Matrices}

The index values of the rock surrounding the diversion tunnel were substituted into the corresponding uncertainty measure functions. Then the uncertainty measure matrices for single-index identification were derived from Formula (2): 


\begin{tabular}{|c|c|c|c|c|}
\hline & $C_{1}$ & $C_{2}$ & $C_{3}$ & $C_{4}$ \\
\hline 11 & 0.65 & 0.35 & $\mathbf{O}$ & $\mathbf{O}$ \\
\hline 12 & 0.07 & 0.93 & O & O \\
\hline 13 & O & $\mathbf{O}$ & 0.4 & 0.6 \\
\hline 14 & 0.15 & 0.85 & O & O \\
\hline 15 & $\mathbf{O}$ & 0.8 & 0.2 & O \\
\hline $1_{6}$ & O & 0.5 & 0.5 & O \\
\hline 17 & O & O & 0.75 & 0.15 \\
\hline 18 & O & O & 0.6 & 0.4 \\
\hline 19 & O & O & 0.75 & 0.15 \\
\hline 10 & O & O & O & 1 \\
\hline 111 & 1 & $\mathbf{O}$ & $\mathbf{O}$ & $\mathbf{O}$ \\
\hline$I_{12}$ & O & O & 0.5 & 0.5 \\
\hline
\end{tabular}

\subsubsection{Weight Vectors of the Indexes}

The weight vectors of the 12 indexes $w^{(i)}=\left(w_{1}^{(i)}, w_{2}^{(i)}, \mathrm{L}, w_{12}^{(i)}\right)$, denoting uniaxial compressive strength of rock, rebound value, $\mathrm{P}$-wave velocity in rock, integrity index of rock mass, volumetric joint count $R Q D$, strength of structural plane, friction coefficient between structural planes, groundwater seepage velocity, angle between main structural plane and tunnel axis, dip angle of main structural plane, and the angle between maximum principal stress and tunnel axis, respectively) were inferred from the single-index measure matrices and Formula (3) as follows:

$w^{(i)}=\left(\begin{array}{llllll}0.0936, & 0.0936, & 0.0936, & 0.1568, & 0.1568, & 0.1568 \\ 0.0663, & 0.0663, & 0.0861, & 0.0279, & 0.0279, & 0.0373\end{array}\right)$

\subsubsection{Comprehensive Measure Evaluation Vector}

The comprehensive measure matrix is calculated as follow:

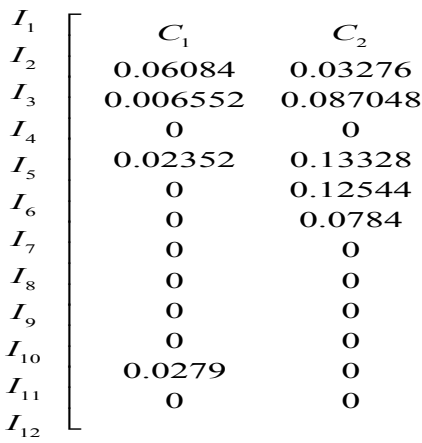

$\left.\begin{array}{cc}C_{3} & C_{4} \\ 0 & 0 \\ 0 & 0 \\ 0.03744 & 0.05616 \\ 0 & 0 \\ 0.03136 & 0 \\ 0.0784 & 0 \\ 0.049725 & 0.009945 \\ 0.03978 & 0.02652 \\ 0.064575 & 0.012915 \\ 0 & 0.0279 \\ 0 & 0 \\ 0.01865 & 0.01865\end{array}\right]$

According to the formula (4), the comprehensive measure vector $u_{i}=\left(u_{i 1}, u_{i 2}, \cdots, u_{i K},\right)^{T}$ is as follow:

$u_{i}=\left(\begin{array}{llll}0.126012, & 0.456928, & 0.319300, & 0.152190\end{array}\right)$

\subsubsection{Results of Confidence Level Identification}

The assessment criteria (Formula (4)) show that the surrounding rock along this tunnel section should be classified as $C_{3}$ surrounding rock, suggesting that this tunnel is somewhat unstable. A survey of the project site shows that the surrounding rock along this section was insufficiently strong because of the occurrence of relatively soft rock micro-cracks and localized plastic deformation and collapse, deformation, or failure that occurred in unsupported areas. The observations are consistent with the results of the comprehensive assessment, which demonstrates the feasibility of the determination of fuzzy reliability indexes used in surrounding rock stability analysis from the results of comprehensive assessment and the validity and reliability of the model proposed in this study.

\section{Conclusions}

The uncertainty-based approach was used for the comprehensive assessment of surrounding rock stability for hydraulic tunnels. This approach mainly considers the stochasticity, concealment, and uncertainty of mechanical parameters of the rock masses. The rock mass parameters were calculated by using the stochastic and fuzzy statistical formula, and a comprehensive evaluation indicator system was proposed. Then an unascertained measure evaluation model for surrounding rock stability in hydraulic tunnel projects was built using the normal distribution function in reliability analysis and the measure function in unascertained mathematics. We arrive at the following conclusions:

(1) Under the comprehensive evaluation indicator system, rock mass integrity coefficient, volumetric joint count, and mass indicators are the most important influence factors. This evaluation indicator system lays the foundation for unascertained measure evaluation models.

(2) The comprehensive evaluation indicator system is most applicable to the complex geological conditions with many rock mass cracks and developed joints. As compared with traditional evaluation approaches, the evaluation indicator system becomes more useful as the number of geological conditions and involved parameters increases.

(3) The model was applied to an engineering case of diversion tunnel of Changdian Hydropower Station in Liaoning Province. The stability grade calculated with the evaluation model was consistent with the field investigation, thereby validating the reasonability of the model built. The biggest innovation lies in the ability of the model to solve the uncertainty of the influence factors of surrounding rock stability assessment.

This study proposed a new method of surrounding rock stability assessment for hydraulic tunnels based on uncertainty theory and engineering practice. The comprehensive evaluation model built provides realistic prediction. However, the model fails to consider environmental factors and internal water pressure, which must be incorporated into the future qualitative and quantitative analyses.

\section{Acknowledgements}

This study was supported by the CRSRI Open Research Program (Program SN:CKWV2015214/KY).

\section{References}

1. Pint O J L., "Deformability of chistou sroeks", Proceeding $2^{\text {nd }}$ conference intermational Science rock mechanies, Beigade, Germany: SPRING, 1970, pp. 491-496.
2. Read S A L, Perrin N D, Brown I R., "Measurement and anslysis of laboratory strength and deformability characteristics of schistose rocks ",Pore $6^{\text {th }}$ in conf rock mech, Montral, Canada: ASCE, 1987, pp. 233-238. 
3. Jaeger J C., "Friction of rocks and stability of rock slope", Geotechnique, 21(2), 2011, pp. 146-152.

4. Ramamurthy T., "Strength modulus responses of anisotropic rocks", Compressive Rock Engineering, 1(1), 2012, pp. 313-329.

5. Amadei B., "Importance of anisotropy when estinating and measuring insitustress in rock", Int J Rock Mech Min Sci Geomech Abstr, 33(3), 2011, pp. 293-325.

6. Singh B., "Comtinum chatacterization of jointed rock masses", Int $J$ Rock Mech Min Sci Geomech Abstr, 33(3), 2013, pp. 311-355.

7. Jose M., "Parameter variability in the toppling stability of rock blocks", South African Institute of Mining and Metallergy, 22(6), 2013, pp. 849-854.

8. Jose M., "Parameter variability in the toppling stability of rock blocks", South African Institute of Mining and Metallergy, 22(6), 2013, pp. 849-854.

9. Stagg R G., "Rock mechanics in engineering practice", John Wiley \& Sons press, American, New York, 1969.

10. L Jing, JA Hudson., "Numerical methods in rock mechanics", International journal of Rock Mechanics \& Mining Science, 39(4), 2002, pp.409-427.

11. Goodman R E,Shi G., "Block theory and its application to rock engineering", Prentice-hall press, American, Englewood Cliffs, 1985.

12. Fangfang Chen, Ning Li, Zhiqiang Zhang., "Back analysis of strength parameters for surrounding rocks of tunnel and its verification", Chines journal of Rock Mechanics and Engineering, 29(1), 2010, pp. 97-103.
13. Hui Wang, Weizhong Chen., "Sensitivity analysis of mechanical parameters to deformation of surrounding rock in Galongla tunnel", Chines Journal of Geotechnical Engineering, 34(8), 2012, pp. 1548-1553.

14. Xinying Liu., "Numerical simulation analysis for surrounding rock stability of unlined high pressure hydraulic tunnels", Journal of Railway Science and Engineering, 9(3), 2012, pp. 45-50.

15. Xing Qu., "Influence of mechanical prameter of surrounding rocks on lining of hydraulic tunnel and its application in engineering", Journal of Xi'an University of Technology, 28(4), 2012, pp. 404410.

16. Youwang Fan, Guangni Xu, Bin Peng., "Stability Evaluation of Adjoining Rock in Large Hydraulic Tunnel ", Soil Engineering and Foundation, 24(5), 2010, pp. 43-46.

17. Yanyan $\mathrm{Li}$, Yingren Zheng, Nan,Kang., "Sensitivity analysis on influencing fators of tunnel stabilityl ", Chinese Jounal of Underground Space and Engineering, 11(2), 2015, pp. 491-498.

18. Yingren Zheng, Yongpu Wang., "Evolution of rockmass pressure theory and researches on tunnel failure mechanism", Tunnel Construction, 23(6), 2013, pp. 423-430.

19. Jian Deng., "Structural reliability analysis for implicit performace function using artufical neural network", Structural Safety, 27(1), 2005, pp. 25-28.

20. Jie Haoi, Kebin Shi., "Analysis on stability of the surrounding rock in tunnel based on block and loose pressure theory ", Chinese Jounal of Underground Space and Engineering, 11(3), 2015, pp.627-631. 